\title{
A eletrificação e a modernização do território do Rio de Janeiro
}

Electrificación y modernización del territorio de Río de Janeiro.

Electrification et modernisation du territoire de Rio de Janeiro

Electrification and modernization of Rio de Janeiro's territory

\section{Matheus Areias da Silva}

\section{Q OpenEdition}

Journals

\section{Edição electrónica}

URL: http://journals.openedition.org/espacoeconomia/17457

DOI: 10.4000/espacoeconomia. 17457

ISSN: 2317-7837

\section{Editora}

Núcleo de Pesquisa Espaço \& Economia

\section{Refêrencia eletrónica}

Matheus Areias da Silva, «A eletrificação e a modernização do território do Rio de Janeiro», Espaço e Economia [Online], 20 | 2020, posto online no dia 27 dezembro 2020, consultado o 29 janeiro 2021. URL: http://journals.openedition.org/espacoeconomia/17457 ; DOI: https://doi.org/10.4000/ espacoeconomia. 17457

Este documento foi criado de forma automática no dia 29 janeiro 2021.

\section{cc) (1) (ㅇ)}

Espaço e Economia - Revista brasileira de geografia econômica est mise à disposition selon les termes de la licence Creative Commons Attribution - Pas d'Utilisation Commerciale - Partage dans les Mêmes Conditions 4.0 International. 


\title{
A eletrificação e a modernização do território do Rio de Janeiro
}

\author{
Electrificación y modernización del territorio de Río de Janeiro. \\ Electrification et modernisation du territoire de Rio de Janeiro \\ Electrification and modernization of Rio de Janeiro's territory
}

Matheus Areias da Silva

\section{Introdução}

1 Este artigo busca debater como a eletrificação influi na organização do território na parte leste da região metropolitana do Rio de Janeiro, a partir de 1879 até 2020. As questões que permeiam este artigo envolvem as esferas sociais, econômicas e políticas, tendo em conta as inúmeras mudanças no espaço urbano através de sua produção e reorganização.

2 Trata-se de apresentar resultados de uma investigação acerca da construção das redes de produção e distribuição de energia elétrica, considerando que as redes técnicas são referências importantes no processo de produção do espaço social, pois desvelam aspectos importantes tanto na relação homem/natureza quanto na constituição de grandes vetores estratégicos de reprodução do poder. Conforme sinalizado por Denis Castilho (2019) ao referir-se às conclusões de Raffestin (1993) sobre as redes técnicas,

elas não são, necessariamente, a exibição do poder, mas são produzidas à imagem do poder. A despeito da grandiosidade de empreendimentos como hidrelétricas, rodovias, pontes, ferrovias, portos etc., há um comando dessas infraestruturas que não se expõe. Ver sem ser visto, diz Raffestin, é o ideal do poder. A análise das redes, por conseguinte, suscita compreender a política, os processos e as ações que lhes dão funcionalidade. (CASTILHO, 2019, p.296)

3 Ainda segundo Castilho, a premissa de que as redes condicionam modernizações e reorganizações no espaço urbano, recebem destaque pela sua relevância, pois,

as redes são condições basilares de expansão da modernização, por viabilizarem um controle e uma fluidez cada vez maiores ao território. Embora alguns de seus efeitos sejam diluídos no cotidiano para garantir o consumo e assegurar as funções do 
poder - que necessita alcançar pontos [do território] para viabilizar a manipulação - essa fluidez, em face do controle é específica a determinados grupos, por isso seletiva. Isso significa que as redes também [podem ser ] vetores de restrições. Elas não podem ser entendidas como sujeitos da ação, conforme destaca Dias (2007), mas como expressões das ações sociais ou, como Santos (1996) já havia alertado, como objetos técnicos operados por sistemas de ações. (CASTILHO, 2019, p.296)

Assim, considerando o papel exercido pelas redes técnicas, investigamos as estratégias da família Guinle e Gafreé em sua disputa com a Light and Power pela primazia da eletrificação do estado do Rio de Janeiro, que caracteriza a trajetória histórica que envolve desde o Brasil Imperial o processo de eletrificação da região. Enfatizaremos a criação da Société Anonyme du Gaz (SAG), em (1886), que iniciou o processo de desenvolvimento histórico da rede elétrica do estado do Rio de Janeiro no leste metropolitano, caracterizado pela sequência empresarial até os dias de hoje: SAG; Light and Power (LIGHT); - Companhia Brasileira de Energia Eletrica (CBEE) - CERJ - (Ampla/ Enel) versus light versus ENERGISA.

\section{A eletrificação enquanto modernização}

5 Os portugueses trouxeram consigo as formas de iluminação utilizadas na Europa, como a lamparina à base de óleos vegetais ou animal, de forma que a iluminação se realizava por meio de lamparinas ou velas feitas de sebo e gordura. No século XIX, algumas cidades brasileiras passaram a ser iluminadas com lâmpadas de óleo de baleia, na mesma medida em que a cidade do Rio de Janeiro passou a receber iluminação pública à base de óleos vegetais e animais.

6 Com o passar dos anos, de acordo com Elisabeth Von der Weid (2003), apesar de ser a Capital do Império do Brasil, o Rio de Janeiro de meados do século XIX era ainda uma cidade acanhada, com aspecto colonial: ruelas estreitas e casas mal construídas, o centro superpovoado e insalubre. Os problemas urbanos eram múltiplos e as soluções eram lentas. Entretanto, o crescimento da cidade foi exponencial com a intensificação do processo de industrialização de setores importante como o têxtil e naval, e sobretudo, a partir do final dos anos 1880 , com os movimentos que culminaram com o fim do escravismo e a instituição da república, tornando a cidade do Rio de Janeiro a capital do País, com o consequente agravamento das questões sanitárias.

7 Em meio às dificuldades e pouco desenvolvimento do traçado urbano, foram-se estabelecendo serviços públicos que procuravam resolver os problemas mais urgentes, como a iluminação a gás, iniciada em 1854, que substituiria a iluminação anterior (iluminação promovida a partir do óleo vegetal/animal); a instalação de uma rede de esgotos, em 1864, e os transporte coletivos sobre trilhos, no final dos anos 1860.

8 Por mais que a iluminação a gás tenha sido inovadora àquele momento, existiam problemas que envolviam os riscos de incêndio, os inconvenientes da fumaça e do cheiro do gás. Com isso, esse tipo de iluminação não causava sensação de segurança para a população que a enxergava com olhares desconfiados.

9 Somente em 1857 o Rio de Janeiro realiza sua primeira experiência com a iluminação elétrica, conforme salientado por Elisabeth Von der Weid:

A primeira experiência de iluminação com energia elétrica no país realizou-se no Rio de Janeiro, com um baile em homenagem a D. Pedro II, em 1857. Em 1879, quatro anos apenas depois da iluminação da Gare du Nord em Paris, a iluminação elétrica permanente chegava ao Rio de Janeiro, com a instalação de quatro lampiões 
na plataforma da estação central da Estrada de Ferro D. Pedro II e dois no salão da entrada, utilizando o sistema Jablochkov - (Esse sistema de iluminação funcionava através de uma lâmpada de arco voltaico alimentada por um forte gerador em corrente alternada, inventado pelo russo Jablochkoff. Ver HUGHES, Thomas, Networks of power. Eletrification in western society. 1880-1930. Baltimore, The Johns Hopkins University Press, 1993. p.87). (WEID, 2003, p.2)

10 A produção e distribuição de energia elétrica foi um dos principais fatores de modernização do território no Brasil, em um momento em que se desenvolvia nos países centrais a revolução técnico-científico, no final do século XIX e início do XX. Historicamente a eletricidade tornou-se um pilar da modernização no Brasil, já que através dela pode-se alterar diversos aspectos da exploração das relações de trabalho buscando a maximização dos lucros por partes dos capitalistas industriais, inicialmente por meio da incorporação do trabalho noturno, e a seguir, pela eletrificação do maquinário. Em outras palavras, a energia elétrica contribuiu para o aumento da produção industrial, por incorporar novas bases de força motriz alterando os fundamentos do maquinário e das tecnológicas até então disponíveis. Consequentemente também intervém nas formas de incorporação do trabalho nos demais setores produtivos, acarretando em um novo patamar de exploração da mão de obra.

11 Assim, os avanços da denominada Segunda Revolução Industrial (revolução dos meios de produção por meio das inovações técnicas e da ciência) refletiram e mudaram significativamente o rumo da industrialização e das relações sociais de produção, sobretudo as relações com a classe trabalhadora. Há de se destacar, ainda, as mudanças que formularam esta nova produção, pois neste período, o ferro, o carvão e a energia a vapor - característicos a primeira fase da Revolução Industrial - passam a ser substituídos pelo ao aço, o petróleo e a eletricidade.

12 As tecnologias introduzidas neste período possibilitaram a produção em massa, a automatização do trabalho - havendo substituição de parte do trabalho vivo (mão-deobra) pelo trabalho morto (maquinário), o que acarretou em certo nível de desemprego e produção de excedentes nas linhas de produção. Os avanços tecnológicos propiciados pela inovação científica e novas matrizes energéticas, como o petróleo, gás e eletricidade permitiram também o surgimento de diversas indústrias, como, por exemplo, a indústria automobilística, a indústria elétrica e a indústria petroquímica, permitindo aumento considerável de empresas e o aprimoramento de indústrias siderúrgicas.

13 No Brasil, a eletricidade advinda deste período é que foi o destaque no processo de modernização tecnológica, já que os efeitos do uso do petróleo e do gás, bem como o amadurecimento de setores industriais que utilizavam as novas matrizes energéticas e as novas tecnologias só ocorreram tardiamente no País (Cardoso de Mello, 1994). Assim, podemos considerar a energia elétrica como uma das principais inovações tecnológicas do Brasil, justamente pelas suas amplas utilizações no desenvolvimento de pesquisas laborais, na substituição da energia a vapor, possibilitando um melhor desenvolvimento das indústrias, bem como diversos instrumentos em que teve interferência, como - a bateria química, a indução eletromagnética, a lâmpada de filamento, a tração elétrica, os motores elétricos, o cabo submarino de comunicações, o telégrafo sem fio e as ondas de rádio - que facilitaram e aprimoraram o setor industrial.

14 A energia elétrica contribuiu também para o desenvolvimento de novas formas de lazer, através da iluminação dos teatros e dos pontos de diversão noturna, permitindo a 
vida social e cultural durante a noite na cidade (LAMARÂO, 2019). Já não era mais o breu de outros tempos, mas um festival de luzes, como o que ocorreu durante a monumental exposição de 1922 comemorando os cem anos da independência do Brasil, considerado um marco na história da cidade, influindo também na ampliação das horas úteis do dia e incentivando os espetáculos noturnos de teatro e música. Vale destacar que os novos usos do gás, não mais utilizado para iluminação, foi redirecionado para a modernização de equipamentos domésticos, passando a alimentar os fogões e eliminando os fogareiros e aquecedores a lenha ou querosene.

De acordo com Elisabeth Von der Weid (2003) a nova tecnologia fascinava a população pela multiplicidade de aplicações e, em especial, pela clareza e nitidez da luz por ela produzida. Em pouco tempo faziam-se várias experiências de sua utilização em diversos setores da vida da cidade, sempre com muita curiosidade e aplauso da população. Rapidamente a sua introdução interferiu em todas as áreas, modificando radicalmente o modo de vida da cidade e de seus cidadãos. o principal uso que alterou o cotidiano da cidade foi a eletrificação dos bondes, tendo em vista que o transporte de massa permitiu o desafogo do centro da cidade, possibilitando a mobilidade de boa parte da população, carente de um transporte rápido e moderno para a época e de atuação regular.

16 O bonde elétrico foi um elemento essencial para a expansão e organização do espaço urbano no Rio de Janeiro, no momento em que houvera a substituição dos bondes que antes eram tracionados por animais. Contudo, o bonde elétrico também apresentou problemas, como: os atrasos, a lotação dos veículos, a sujeira, o custo da tarifa e os acidentes ocasionados. Mesmo assim, por mais que houvessem problemas, os bondes proporcionaram outro patamar de fluxo na cidade, tornando-a mais diversificada, articulada, com maior grau de complexidade e mobilidade urbana.

17 Assim, vale também o destaque para as comunicações telefônicas, que aproximaram as pessoas e, juntamente com os transportes eletrificados, reduziram as distâncias na cidade, contribuindo com a sua expansão física. Tudo isso permitia um maior rendimento do tempo, multiplicando as horas úteis do dia. E, sobretudo, do ponto de vista do lazer, a chegada do cinematógrafo revolucionou os espetáculos e o gramofone (toca-discos elétrico) que mudou o clima dos mais variados ambientes (LAMARÃo, 2019).

18 Concomitante às evoluções, de acordo com Amara Silva de Souza Rocha (2009), a eletricidade remodelou o espaço urbano e tornou-se um recurso de investimento imobiliário, o que contribuiu para a valorização de áreas até então praticamente despovoadas. Copacabana e Ipanema, quando ainda eram "desertos e distantes areais", foram fartamente iluminadas, enquanto outras áreas densamente povoadas muitas vezes não possuíam sequer iluminação a gás. Empresários do setor imobiliário trataram de adquirir terrenos ao terem acesso às informações privilegiadas sobre a geografia da eletrificação, ou até mesmo participaram de decisões na definição das zonas que seriam iluminadas.

19 Vala a pena resgatar afirmações de época que assinalavam que, « atualmente a energia elétrica faz parte do cotidiano das pessoas, iluminando casas e ruas, principalmente a partir da reforma instituída pelo prefeito Pereira Passos, no início do século XX », como afirmou Andre Luis Mansur (2017). Contudo, historicamente, de acordo com as análises do livro "Energia elétrica e urbanização na cidade do Rio de Janeiro", produzido pelo Centro da Memória da Eletricidade do Brasil, pôde-se observar uma crítica enfática 
no que se refere à negligência do prefeito Pereira Passos em relação aos subúrbios e seus moradores que foram expulsos do centro do Rio. Ou seja a segregação espacial passa a ter mais um elemento de produção de desigualdades, já que como assinalara Leila Dias (2000) as redes técnicas também podem ser portadoras de exclusão social.

Ainda de acordo com Andre Luis Mansur,

ao organizar a cidade a partir da área central no sentido da Zona Sul, a reforma inaugurou uma prática que viria a ser seguida até o final da Primeira República, em 1930, e de certo modo até os dias de hoje: o privilégio explícito dado a essa região no que tange à oferta de equipamentos coletivos em detrimento de outras áreas, sobretudo nos subúrbios. Pode-se verificar que enquanto a iluminação elétrica no centro, zona sul e parte da zona norte era intensificada, com apoio do poder público e com disputas entre empresas privadas, como a que ocorreu entre a Light e o grupo Guinle, nos subúrbios e na área rural da cidade os bondes ainda eram puxados a burro e a população só tinha acesso à luz elétrica quando fornecida pelo gerador de alguma empresa instalada no local, como nos casos do Matadouro de Santa Cruz e da Fábrica Bangu. (MANSUR, 2017, p.3-4)

Amara Silva de Souza Rocha (2009) aponta que, se por um lado a eletricidade encantou muita gente, independentemente da origem social, por outro tornou-se uma valiosa mercadoria cujo acesso não se realizou de forma homogênea, em outras palavras,

a cidade, apesar da farta iluminação elétrica concentrada em espaços valorizados e da aparência de grande metrópole, permanecia ainda mais contraditória do que antes. A estética moderna, ao mesmo tempo em que expunha um ideal almejado, tornava-se um espelho que continuava refletindo uma sociedade com "ares provincianos". Essa visão fica clara para a própria elite, para a qual a cidade, apesar de "modernizada", continuava misteriosa. Como dizia o texto publicado na Revista Fon-Fon, em 9 de março de 1912: “(...) numa mistura de tipos, vagabundos e homens de negócio, ninguém fala franco, antes recatadamente (...) tudo em contraste com a pompa berrante dos edifícios e dos candelabros de iluminação." (ROCHA,2009, p.6)

\section{A eletrificação enquanto Rede Técnica.}

Primeiramente, vale apontar que ao utilizar o termo - eletrificação - este está referindo-se ao conceito de energia elétrica. Tal conceito expressa a descoberta inicial de Tales de Mileto, um filósofo grego, que no século VI a.c no ato de esfregar um pedaço de âmbar na pele de um animal pôde perceber que o atrito gerava no âmbar a atração de pequenos objetos como pedaços de palha e lã, dando origem ao fenômeno chamado de eletricidade estática. Posteriormente outros cientistas se debruçaram sob o tema e fizeram com que fosse possível o avanço tecnológico dos dias atuais.

A energia elétrica, conceitualmente, é aquela capaz de criar voltagem entre dois pontos (também conhecido como "diferença de potencial elétrico"), o que permite a criação de uma corrente elétrica entre dois pontos, sendo um fluxo ordenado de partículas portadoras de carga elétrica do ponto A ao ponto B. Caracteriza-se por ser amplamente utilizada devido ao seu potencial de transporte e pelo baixo nível de perda de energia durante as conversões.

Atualmente a eletricidade tornou-se uma das principais fontes de energia utilizadas, a qual pode ser gerada e obtida através das termoelétricas, usinas hidroelétricas, usinas eólicas e usinas termonucleares. A ampla porcentagem de utilização da fonte hidrelétrica como principal matriz energética no Brasil pode ser visualizada no gráfico representado na figura 1, realizado pela ANEEL/ABSOLAR referente ao ano de 2019: 


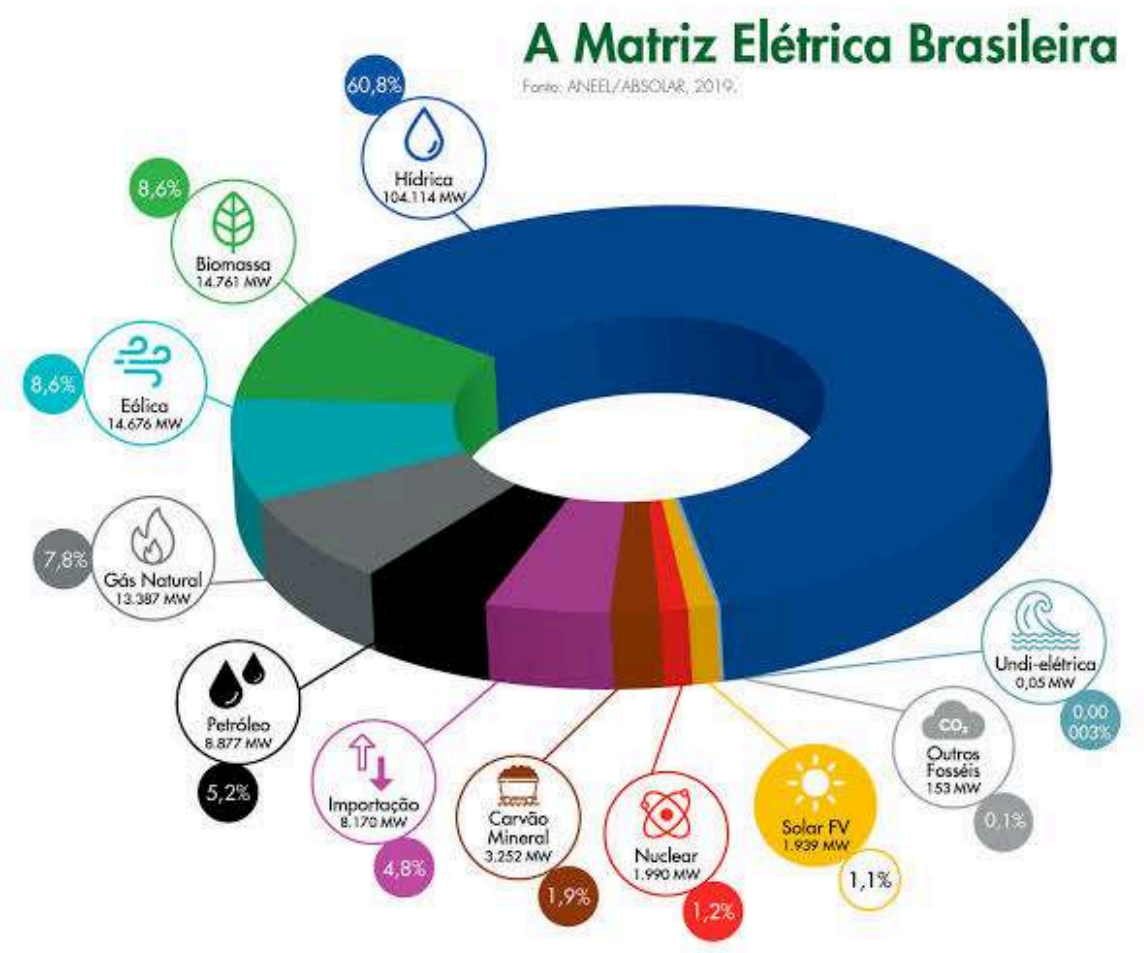

FONTE: http://www.e-sage.com.br/como-esta-o-mercado-de-energia-solar/matriz eletrica-brasileira/

Logo, pode-se estabelecer como exemplo que uma estrutura que conjuga a produção de energia elétrica às linhas de transmissão de transporte de energia para o consumidor final é chamada de rede técnica, referindo-se a este setor produtivo. No que se refere à técnica, Milton Santos (1996) aponta para, segundo Marx, "o que distingue épocas econômicas umas das outras não é o que se faz, mas como se faz, com que instrumentos de trabalho" (Marx, O Capital, apud SANTOS, 1996: p.132). Ou seja, Milton Santos argumenta que do ponto de vista da Geografia, a técnica é um importante modo de relação entre homem e natureza, entre homem e o espaço geográfico; onde através dessa relação "as técnicas são um conjunto de meios instrumentais e sociais, com os quais o homem realiza sua vida, produz e, ao mesmo tempo, cria espaço" (SANTOS, 1996, p.25)

Ainda sobre o conceito de técnica, de acordo com Silveira (2003) estas expressam por meio dos objetos técnicos seu conteúdo histórico e, em cada momento de sua existência, da sua criação à sua instalação e operação, revelam a combinação em cada lugar das condições políticas, econômicas, sociais, culturais e geográficas que permitem seu aproveitamento.

Quanto à concepção de rede, Curien e Gensollen (1985) assinalam que a rede é toda infraestrutura, que permitindo o transporte de matéria, de energia ou de informação, se inscreve sobre um território onde se caracteriza pela topologia dos seus pontos de acesso ou pontos terminais, seus arcos de transmissão, seus nós de bifurcação ou de comunicação.

Milton Santos expõe uma segunda definição ao se referir à rede. Definição que trata de seu conteúdo, de sua essência, em outras palavras, a rede, segundo Santos, "é também 
social e política, pelas pessoas, mensagens, valores que a frequentam. Sem isso, e a despeito da materialidade com que se impõe aos nossos sentidos, a rede é, na verdade, uma mera abstração".(SANTOS, 1996, p.209).

Após a exposição dos conceitos pode-se dizer que a eletricidade é uma modernização tecnológica que se dissemina por meio de uma rede técnica que tem por objetivo produzir, conduzir e entregar energia elétrica ao consumidor final. Por exemplo, através das grandes obras de engenharia aliadas aos componentes materiais (objetos técnicos) que fazem parte da construção de uma estrutura elétrica torna-se possível interagir com a condução elétrica para com isso utilizar a rede capaz de interligar o aparato tecnológico com a sociedade, atendendo-a como consumidores.

De acordo com o diálogo de Márcio Cataia com Thomaz Parker Hughes, pode-se constatar tal análise baseada na estrutura do sistema elétrico norte-americano, onde é possível observar a exemplificação da complexa cadeia produtiva do sistema elétrico. Assim,

ao estudar o sistema elétrico norte-americano, Thomas Parker Hughes propõe sua compreensão analítica a partir de um tripé que resulta da combinação (i) de grandes obras de engenharia, tais como as hidroelétricas, (ii) da distribuição dos fluxos, por meio das redes elétricas, e (iii) de empresas de gestão comercial para ligar a oferta e a demanda. Cada um desses grandes agentes do macrossistema possui uma coerência interna e canais de comunicação com os outros grandes agentes do sistema. (CATAIA, 2019. p. 581-582)

31 Ou seja, a rede técnica traduz, de acordo com alguns exemplos de Marcio Rufino, desde "Infraestruturas rodoviárias e ferroviárias, redes de transmissão de energia, de comunicações, informações, etc.” (RUFINO, 2019, p.276)

\section{Eletrificação do Rio de Janeiro - um breve histórico.}

32 A eletrificação do Rio de Janeiro passou por diversas etapas, em épocas diferentes, levando em consideração cada contexto histórico. Inicialmente o processo de eletrificação no estado ocorre na cidade de Campos dos Goytacazes, como base na geração termoelétrica nas usinas de cana de açúcar, e posteriormente na cidade do Rio de Janeiro, ainda no período imperial. Mas é na última década do século XIX, quando a cidade já era Distrito Federal do Brasil republicano, que a eletrificação se desenvolve comercialmente. Assim, considerando a linha temporal do processo, devemos ter em conta o processo na cidade do Rio de Janeiro, antes de enfatizar especificamente o leste metropolitano.

Como já mencionado anteriormente, a primeira experiência oficial com energia elétrica foi iniciativa de D. Pedro II. Em 1879 fora inaugurada a iluminação da antiga Estação da Corte da Estrada de Ferro Central do Brasil. $O$ diretor da estação na época era o jovem engenheiro Francisco Pereira Passos.

Vale ressaltar que a apresentação do uso da energia como modernização fora amplamente disseminado no evento histórico que ocorreu em Paris, em 1889, denominado "Exposição Universal". Este evento atraiu a atenção do mundo para a nova tecnologia (eletricidade) e seu potencial de utilizações, como sendo capaz de proporcionar mais luz e velocidade aos novos tempos. Este evento pôde potencializar os interesses acerca da energia elétrica naquele momento em diversos países. A nova tecnologia foi adotada rapidamente, de forma quase simultânea, nos EUA, na 
Europa e na América Latina, integrando o cenário das reformas urbanas da virada do século XX.

Com a instituição da Republica no Brasil, o Rio de Janeiro torna-se Distrito Federal, ou seja, deixa de ser um município neutro, que abrigava a corte imperial. Com isso, houveram incentivos e desdobramentos para a expansão da energia elétrica, bem como estímulos para expansão das concessões de serviços públicos em geral.

A empresa proprietária da concessão de fornecimento de iluminação pública era a Société Anonyme du Gaz (SAG), empresa belga que desde a sua fundação, em 1886, mantinha uma relação contratual direta com o governo imperial. Com o novo governo republicano a concessão começa a ser revista, no sentido de que fosse ampliada a capacidade de geração de energia, pois a empresa não conseguiu dar conta de construir a Represa de Ribeirão das Lages, no município de Piraí, distante $76 \mathrm{Km}$ da cidade do Rio de Janeiro. Mas, assim mesmo, a SAG ainda conseguir permanecer por algum tempo com o privilégio para explorar a iluminação pública.

37 Em janeiro de 1903, a Inspetoria de Iluminação definiu as ruas e praças que deveriam compor a primeira zona da cidade a receber iluminação elétrica. Cabia à SAG construir a rede de distribuição e dar início a construção da represa e geradora de energia. Contudo a empresa, não tendo recursos para dar conta da empreitada, perdeu a concessão e a mesma foi cedida a outra empresa. Em julho de 1904 é criada na cidade a "Rio de Janeiro Tramway - Light and Power Company Limited". A empresa inicia suas atividades com um aporte de 4 milhões de dólares, obtidos pela associação da empresa criada pelo Engenheiro Pearson, nos EUA, com os grupos financeiros de Toronto, Canadá (BERENGER, 2008:44). A Light obteve apoio do então presidente da República, Rodrigo Alves, e do prefeito Pereira Passos, e a partir deste apoio, a empresa iniciou o projeto de construção da Represa e acabou por monopolizar o setor e obter a primazia da exploração de energia elétrica da cidade.

Com o apoio governamental à Light, a SAG foi sendo enfraquecida, e as manobras políticas possibilitaram que no mês de julho de 1904 o lobby exercido pela Light nos bastidores dos poderes municipal e federal eliminasse as condições de operação da companhia belga.

Para esse ambicioso objetivo de monopolizar o setor de fornecimento de energia elétrica a Light se dedicou a captar recursos no mercado financeiro internacional, visando adquirir a empresa que possuía concessões de energia elétrica. E logo o grupo canadense adquiriu o controle acionário da empresa belga, e em 1907, 90\% das ações da SAG pertenciam à Light, que passava a controlar o fornecimento de energia elétrica para iluminação da cidade do Rio de Janeiro.

40 Após conquistar seu espaço, a Light incorporou a eletricidade ao cenário da belle époque carioca $^{1}$ (LAMARÃO, 2019) e tornaram-se constantes os apelos para que a população frequentasse o centro da cidade também à noite, de forma a gozar dos benefícios da metrópole moderna - do ponto de vista da eletricidade - e fazer do passeio um programa familiar. Embora houvesse toda a euforia pela nova tecnologia, a cidade ainda convivia com muitos problemas, como questões que envolvem infraestrutura e principalmente a falta do saneamento básico adequado para o número de pessoas que abrigara à época.

41 Amara Silva de Souza Rocha (2009) referindo-se à primeira década do século XX, a maior parte da população carioca estava concentrada nas áreas centrais, onde a 
economia voltada para o abastecimento de alimentos dividia espaço com estabelecimentos bancários, casas comerciais e moradias. 0 afluxo crescente de migrantes e imigrantes à procura de trabalho e de melhores condições de vida agravava ainda mais os sérios problemas de infraestrutura da capital. O saneamento da cidade era uma preocupação nacional e a iluminação não atendia a todos, haja vista que essas são questões que permeiam até os dias atuais. As deficiências de infraestrutura e serviços urbanos foram um dos aspectos que serviram como ponto de partida para as reformas do então prefeito Pereira Passos. De acordo com Amara Silva de Souza Rocha,

Além disso, havia o interesse em reordenar o espaço urbano de forma a facilitar o fluxo dos grandes negócios imobiliários, financeiros e comerciais. Por conta de todos estes fatores, teve início um projeto de remodelação urbana, amparado pela doutrina da medicina social em vigor e inspirado nas reformas de Paris, então modelo incontestável de urbanismo. Entre os anos de 1902 e 1906, o prefeito Pereira Passos capitaneou uma verdadeira "cirurgia", com o desmonte de morros, desapropriações e destruição de várias moradias, igrejas e outras construções. 0 objetivo da empreitada era abrir uma grande avenida que funcionaria como uma artéria, rasgando o centro da cidade e definindo novos rumos para o espaço urbano. Ao lado de todas essas reformas, a eletrificação e a nova iluminação foram importantes para compor o cenário da capital modernizada. (ROCHA, 2009, p.3)

Num momento de intensas alterações na estrutura urbana da cidade, os jornais da época noticiavam que as mudanças, rompendo com o antigo Rio de Janeiro colonial e transcendendo à novos olhares e perspectivas, promoveram melhorias significativas na cidade. Contudo, também apresentava problemas ao não priorizar o acesso às tecnologias, ao bem-estar, ao fornecimento de energia elétrica nos domicílios, ao saneamento básico, etc. Enfim, foram obras de embelezamento do centro da cidade em detrimento das demais zonas que se tornaram periféricas, conforme pode ser constatada nas reportagens mostradasa na figura 2.

\section{Segundo Lamarão, a Reforma foi considerada}

Símbolo da instauração da ordem burguesa capitalista no Rio de Janeiro, a reforma Passos acelerou o processo de hierarquização social e especialização funcional que se desenrolava desde pelo menos o início do século XIX, definindo as áreas ocupadas pelas camadas mais abastadas e por aquelas de menor poder aquisitivo, e delimitando os espaços do trabalho e da moradia. Momento da europeização da cultura carioca - e brasileira - e de padronização de hábitos e comportamentos coletivos, a reforma, ao impor uma modernização autoritária e de fachada, só fez aprofundar as desigualdades sociais herdadas do recente passado colonial escravista. (LAMARÃO, 1997, p.203) 
Figura 2 : Notícias da Reforma Pereira Passos (1902-1906)

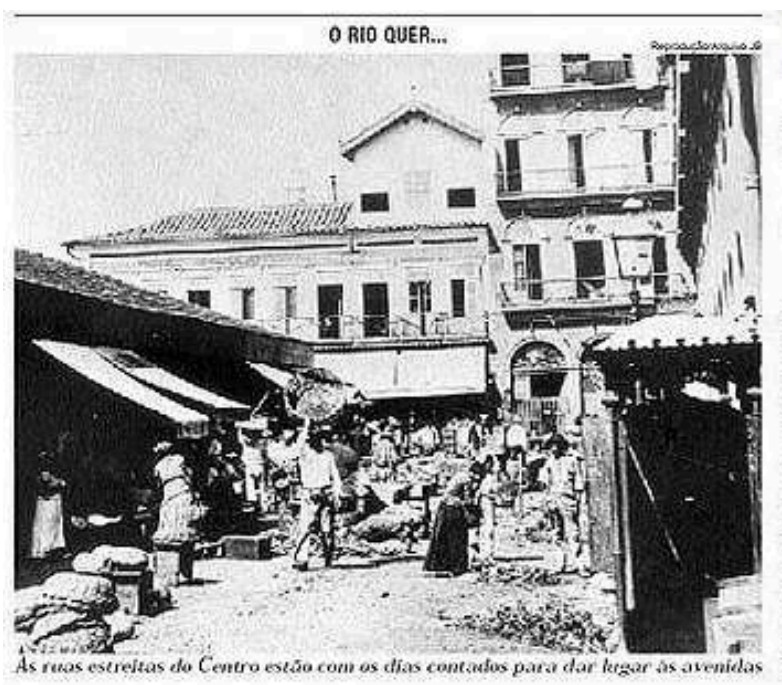

\section{Pereira Passos manda demolir o Rio colonial}

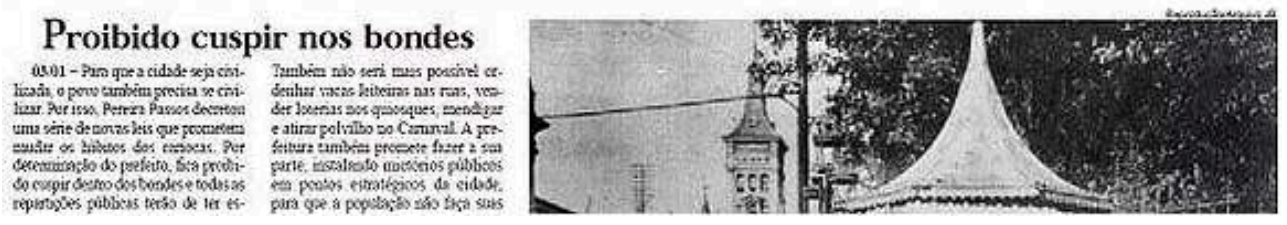

FONTE: https://www.conscienciatranquila.com/single-post/2014/05/05/HIST\%C3\%93RIAS-DAPEQUENA-\%C3\%81FRICA-A-Reforma-Urbana-de-Pereira-Passos

Como esperado de uma intensa transformação na cidade, diversas empresas sentiramse atraídas para investir e atuar em sua modernização. A disputa pela concessão do fornecimento de energia elétrica, que envolveu uma acirrada competição entre as empresas das famílias Guinle / Gaffrée e a Light pelo fornecimento de energia elétrica.

\section{A eletrificação no lado leste da Baía da Guanabara - panorama histórico até a atualidade.}

46 Há uma peculiaridade que envolve os municípios do lado leste da Baía da Guanabara, onde se situa a cidade de Niterói e seu entorno, e que se destaca a atuação do grupo Guinle/ Gaffrée. O objetivo deste tópico será de comentar a concorrência entre os Guinle/Gaffrée versus Light e apontar para o seu desfecho histórico.

47 As questões que se destacam são as seguintes: quem são os empresários que lideram o grupo Guinle/ Gaffrée? Qual a influencia deste grupo em diferentes escalas econômicas? Por que eles foram importantes para desenvolver a eletrificação da parte leste da Baía de Guanabara? Quais foram as suas ações frente à Light que fizeram jus à concorrência? Como se deu o desdobramento histórico de ascensão e queda das empresas do grupo Guinle/ Gaffrée? Qual é o panorama histórico da eletrificação até a atualidade?

Pode-se dizer que, historicamente a ação dos Guinle/Gaffrée no Brasil é quase imensurável. Desde o final do século XIX e ao longo do século XX, as famílias gaúchas de Eduardo Guinle, financista na corte imperial e no início da república, e Cândido Gaffrée, empresário e investidor na economia nacional, realizaram inúmeros empreendimentos em diversos ramos da economia. Como exemplo, os negócios de Guinle e Gaffrée se 
ramificaram na construção de estradas, ferrovias, no setor imobiliário e em 1888 a dupla de empresários deram o passo que os tornariam os maiores investidores da época: a concessão para reformar e administrar o Porto de Santos, que veio a ser o escoadouro de toda a produção de café do País. Durante 92 anos, as famílias abasteceram seus cofres com o dinheiro advindo da exploração comercial do porto, que chegava a render 24 bilhões de dólares por ano, em valores de hoje. $O$ cálculo consta no livro "Os Guinles" (ed. Intrínseca, 2015), do historiador Clóvis Bulcão.

Com tamanha fortuna ambos espalharam os seus nomes em vários outros campos de atividades do país, desde a construção de hospitais (Hospital Gaffrée e Guinle, na cidade do Rio de Janeiro), hotéis (Copacabana Palace), construção civil (empreiteiros na Companhia Siderúrgica Nacional, a CSN), portos (o complexo portuário de Santos), acervos de museus (Museu Imperial e Histórico Nacional), arquitetônico e imobiliário (Palácio das Laranjeiras, a Granja Comary), financeiro (Banco Boavista), tendo ainda eletrificado o Elevador Lacerda (Salvador), patrocinado pesquisas de petróleo à época de Getúlio Vargas e até investido nas carreiras grandes músicos brasileiros da Orquestra Sinfônica Brasileira.

Guinle e Gafrée também foram reconhecidos por investir no setor elétrico, inicialmente a dupla comercializava materiais elétricos e representavam vários fabricantes de equipamentos elétricos. Com essa esperiência atuaram na construção da Usina Hidrelétrica de Alberto Torres no rio Piabanha, na altura do município de Areal, RJ, e executaram projetos encomendados por terceiros em diversos estados. Nesse período fundaram a Companhia Brasileira de Energia Elétrica - CBEE. A partir deste panorama pode-se perceber a importância destes dois atores nos mais diversos âmbitos econômico-espaciais. Há uma questão pertinente que vale a penas ser resgatada, a origem desses empreendedores.

51 Cândido Gaffrée, figura 3, é filho de imigrantes franceses estabelecidos na província do Rio Grande do Sul, veio para o Rio de Janeiro em 1870 para tentar a vida no comércio com o dinheiro que trouxe do Rio Grande do Sul. No ano de sua chegada ao Rio de Janeiro associou-se a José Marques Nunes e Carlos Pereira Rego para a criação da Nunes, Gaffrée \& Cia no decorrer do ano de 1870, denominada Aux Tuileries. A firma que fora criada após sua chegada tinha o objetivo de comercializar principalmente tecidos no varejo.

52 Eduardo Palassin Guinle, figura 4, amigo de infância de Gaffrée, vivia na mesma província, o Rio Grande do Sul, antes de se deslocar para o Rio de Janeiro. Além disso, Guinle também é filho de imigrantes franceses e em 1871 entrou como sócio da Aux Tuileries em substituição a Carlos Pereira Rego. 
Figura 3 : Cândido Gaffrée (1845-1920)

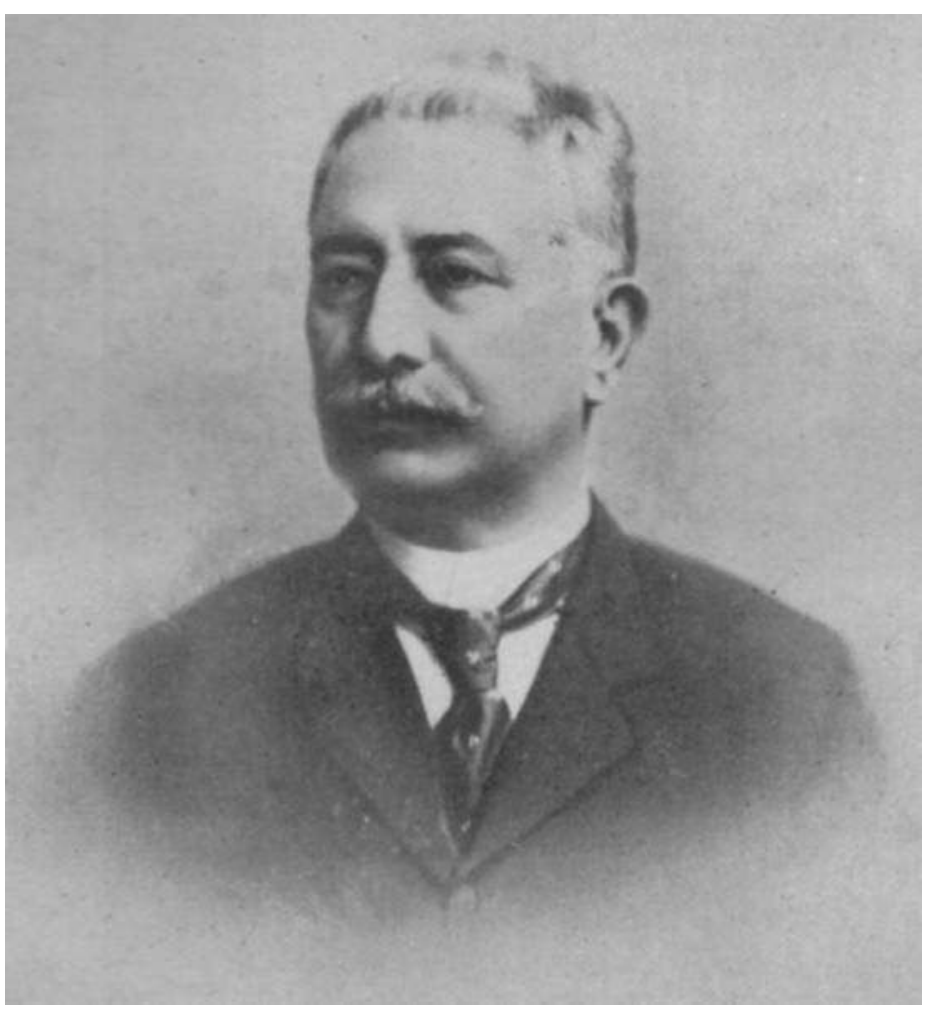

FONTE: http://www.novomilenio.inf.br/santos/fotos223.htm - Reprodução do livro Docas de Santos Suas origens, lutas e realizações, de Hélio Lobo, Typ. do Jornal do Commercio - Rodrigues \& C. - Rio de Janeiro/RJ, 1936, página 366-a 
Figura 4 : Eduardo Palassin Guinle (1846-1912)

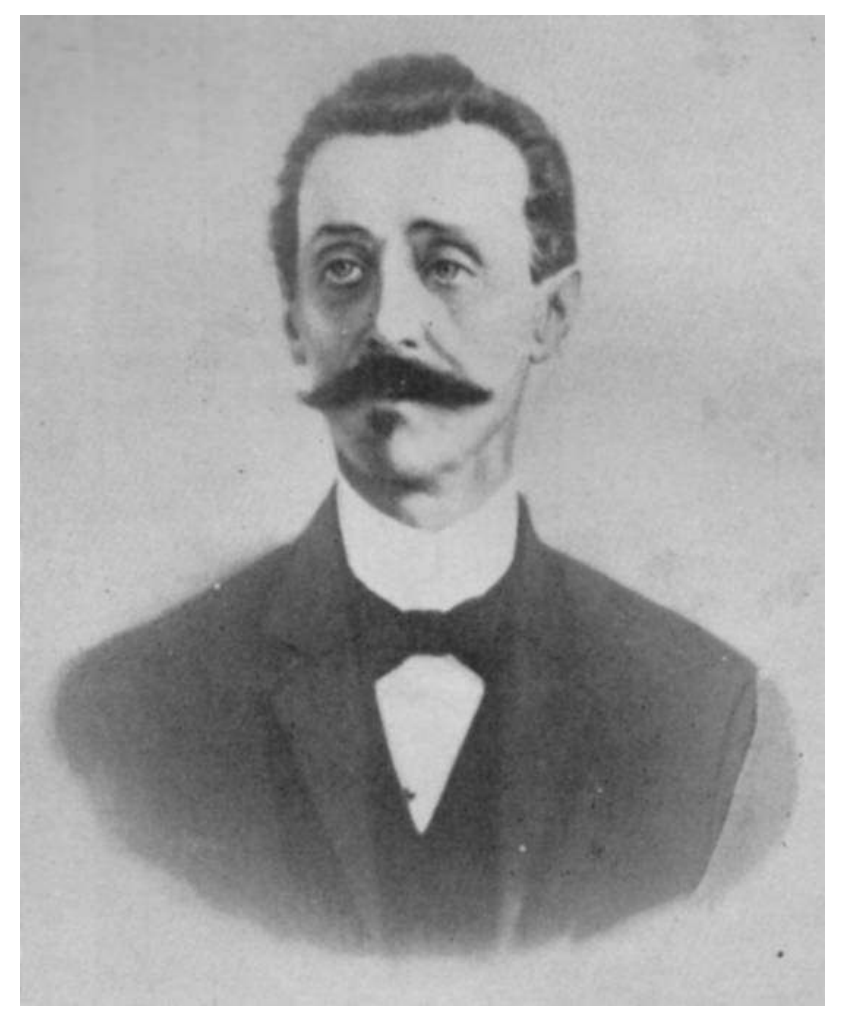

FONTE: http://www.novomilenio.inf.br/santos/fotos223.htm - Reprodução do livro Docas de Santos Suas origens, lutas e realizações, de Hélio Lobo, Typ. do Jornal do Commercio - Rodrigues \& C. - Rio de Janeiro/RJ, 1936, página 338-a

54 A partir do momento em que se tornaram sócios, Eduardo e Cândido almejavam outras formas de expandir suas negociações, mas somente em 1872 assumiram a firma cujo nome era Gaffrée \& Guinle, com o objetivo de comercializar não só tecidos no varejo mas também os produtos importados, ou seja, houve uma transformação na firma ao se tornar importadora de mercadorias. ampliação e exploração do Porto de Santos. No mesmo ano fundaram a Gaffrée, Guinle \& Cia. para a realização das obras e melhoramentos do Porto, que só se tornou possível graças aos acordos que envolviam concessões do Estado. O Porto de Santos tornou-se um investimento muito rentável, com objetivos que envolvem uma política capitalista de instauração do sistema portuário. A dupla tornou-se monopolista das operações portuárias, passando a controlar todas as operações de embarque e desembarque de mercadorias, a manutenção dos navios, o controle dos armazéns, a movimentação interna de mercadorias, etc.

O resultado deste investimento no Porto de Santos alavancou a renda e capacidade de exploração de outros horizontes econômicos, por exemplo a fundação da Gaffrée, Guinle \& Velloso, em 1889, para a exploração agrícola, principalmente plantio de café, assim como a Fábrica de Fósforos Cruzeiro, também em 1889, para a fabricação de fósforos e em 1903 fora fundada a Aschoff \& Guinle, uma casa de importação e exportação de vários materiais, inclusive materiais elétricos. 
57 Após a fundação da Aschoff \& Guinle (1903) os sócios Gaffrée e Guinle efetivaram seus interesses no setor elétrico. Com isso, a família Guinle fundou em 08 de março de 1904 uma nova firma, intitulada Guinle \& Cia, com o objetivo de substituir a antiga empresa numa liquidação amigável. A nova firma teve seu capital ampliado devido ao investimento de três integrantes da família Guinle, constituindo a sociedade somente com membros dos Guinle: Eduardo Guinle, Guilherme Guinle e Carlos Guinle.

Logo, a Guinle \& Cia desenvolveu seus próprios projetos no setor da eletricidade, em 1906 foram capazes de fazer duas grandes obras de engenharia: em São Paulo iniciaram a construção da Usina de Itatinga, para atender as necessidades do Porto de Santos; assim como iniciaram a construção da Usina de Piabanha, em Alberto Torres, Rio de Janeiro, com o objetivo de fornecer energia elétrica para a cidade.

59 Fora neste momento que se desenvolve a atuação da empresa no leste metropolitano, isto é, a atuação da Guinle \& Cia na construção da Usina de Piabanha, que atendia àquela época uma pequena parte do território fluminense, beneficiando, sobretudo, as cidades de Niterói, São Gonçalo, Petrópolis e Magé. A Usina, figura 5, constituiu-se num exemplo da dimensão dos investimentos dos Guinle já que se tratava da segunda maior hidrelétrica do país, perdendo apenas para a usina de Fontes (figura 6), construída pela The Rio de Janeiro Tramway Light and Power Company Limited.

Figura 5 - Usina de Piabanha (Período de construção e início das atividades: 1906-1908):

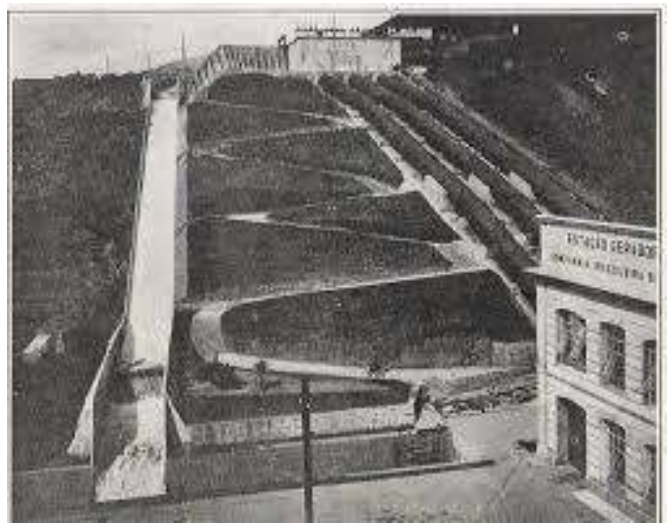

FONTE: http://www.ub.edu/geocrit/Simposio/cMOliveira_Aindustria.pdf 
Figura 6 - Usina de Fontes (Período de construção e início das atividades: 1904-1908):

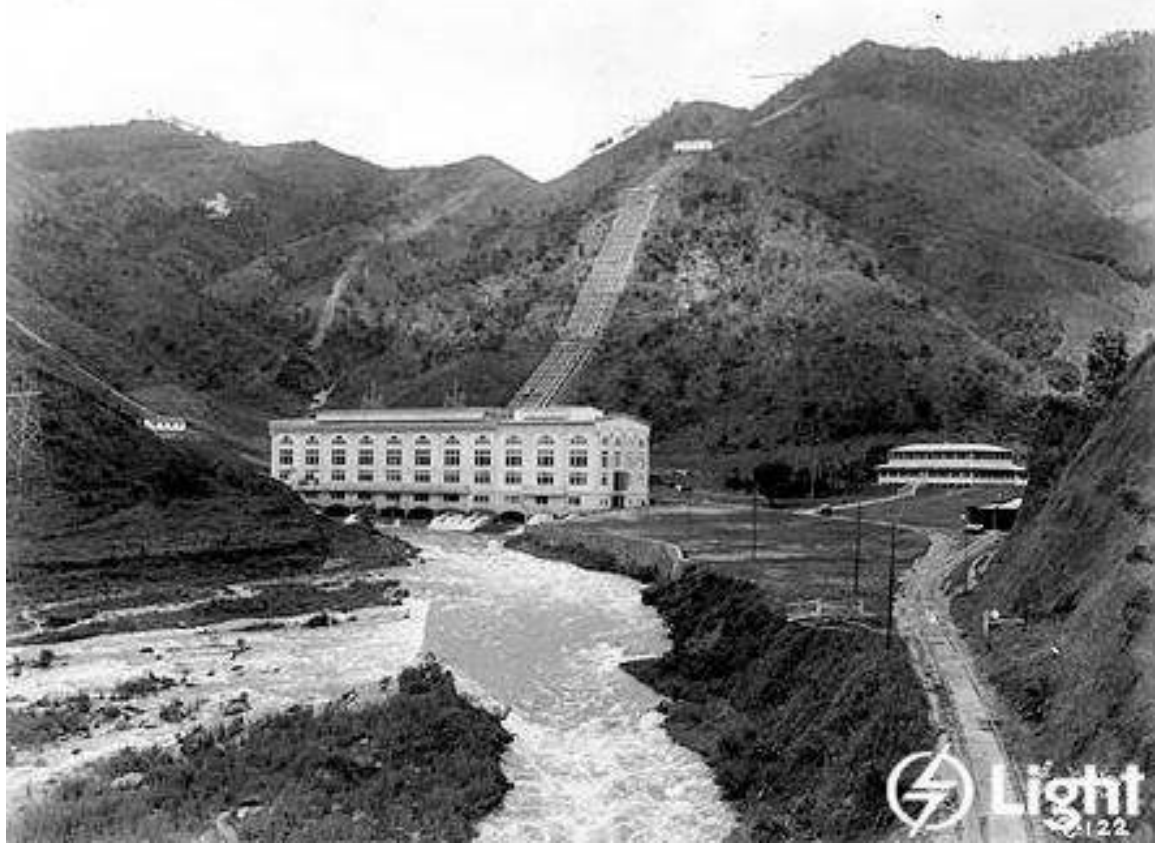

FONTE: https://www.trilhosdorio.com.br/forum/viewtopic.php?f=90\&t=119

A Guinle \& Cia e a The Rio de Janeiro Trammway Light and Power Co. Ltd., entre os anos de 1905 e 1915, travaram uma disputa acirrada pela primazia do fornecimento de energia elétrica ao mercado carioca. Contudo, a história destas duas empresas aponta que houve a possibilidade de associação empresarial e com isso haveria a união de duas potências do setor elétrico. A Guinle \& Cia fora então reconhecida pela empresa canadense como um forte concorrente, mas isso, empresarialmente, poderia acarretar um desgaste para ambos, já que a concorrência poderia ocasionar perda de lucros. Por isso, objetivando maximizar seus horizontes e alcances, estabeleceram uma aliança estratégia para que a Guinle\&Cia se associasse a The Rio de Janeiro Trammway Light and Power Co. Ltd no projeto de fornecimento de energia elétrica ao mercado carioca.

No entanto, por mais que houvesse a possibilidade de associação, a Guinle \& Cia tinha um objetivo mais ambicioso. Ao encarar a proposta da The Rio de Janeiro Trammway Light and Power Co. Ltd como desvantajosa e apresentar um projeto próprio para o setor elétrico do Rio de Janeiro, a Guinle \& Cia reafirmou seu desejo pela disputa da hegemonia do setor elétrico e então fundou uma nova empresa, a Companhia Brasileira de Energia Elétrica (CBEE) em 1909, tendo como objetivo cuidar do serviço de produção, transmissão e distribuição de eletricidade dos Guinle.

62 A fundação da CBEE ocorreu como uma Sociedade Anônima e isso estava muito relacionado às vantagens estabelecidas pela legislação do período para este tipo de empresa. É bem verdade que naquela época (século XX) os Guinle alcançaram o feito de serem considerados dentre as maiores autoridades técnicas no setor elétrico brasileiro, pois traçaram estratégias para expandir seus mercados, fundaram empresas, negociavam concessões com o Estado e com isso alavancaram seu patrimônio. Tendo em vista os decretos e concessões, pode-se dizer que o grupo Guinle \& Cia foi beneficiado e conseguiu manter a CBEE, como, por exemplo, os decretos nº. 7.456, de 15 de julho de 1909, e 7.890, de 10 de março de 1910, por meio dos quais foram transferidas 
para a CBEE as concessões feitas a Guinle \& Cia. De acordo com os decretos, o primeiro destina-se aos serviços relativos às instalações hidroelétricas na Usina Alberto Torres, no Estado do Rio de Janeiro, e para o aproveitamento da força hidráulica do rio de Itapanhaú, no Estado de São Paulo enquanto o segundo decreto concede o aproveitamento da força hidráulica do rio Paraguaçu, no Estado da Bahia.

Vale destacar que, no estado do Rio de Janeiro, a Guinle \& Cia tinha contratos com o município de Niterói no que consiste o fornecimento de energia elétrica para iluminação pública, além do suprimento de energia elétrica em Petrópolis, Magé e São Gonçalo. Assim, associado com a Société Anonyme de Travaux et d'Entreprises au Brésil, pôde estabelecer um contrato com o Ministro da Indústria, Viação e Obras Públicas para suprimento de energia elétrica a serviços públicos federais nessas cidades.

Cabe dizer que, de acordo com Cláudia Hansen (2012) a CBEE, no período de 1904 até 1913 (momento em que a disputa fora mais acirrada) não apresentou fragilidade econômico-financeira frente ao capital estrangeiro, a CBEE detinha capital suficiente para enfrentar a concorrência, contudo, a disputa deu-se também no espaço político e jurídico, com isso, a CBEE fora enfraquecida.

66 No contexto da concorrência pelo setor elétrico a política toma força como um dos principais pilares da ascensão ou enfraquecimento das empresas. Hansen (2012) aponta que com Nilo Peçanha e Serzedelo Corrêa à frente dos cargos executivos federal e municipal, a CBEE se viu envolvida nas disputas inter-oligárquicas, na chamada Primeira República. Além disso, muito próximo aos dois ocupantes destes cargos públicos estava Raul Fernandes, que era "homem de confiança" e advogado dos Guinle. Essa estratégia política, nos momentos de avanço do nilismo (referência à Nilo Peçanha), tanto no cenário estadual quanto no federal e municipal, criou possibilidade de alavancar o enfrentamento da Guinle\&Cia/CBEE diante da The Rio de Janeiro Trammway Light and Power Co. Ltd.

No balanço histórico que permeia períodos de ascensão e queda das duas empresas, a Light e a CBEE, observam-se favorecimentos políticos. Por exemplo, no período de 1906 - 1908 - momento em que ambos faziam os seus primeiros investimentos para poderem fornecer energia elétrica ao Rio de Janeiro. Neste período, em que o nilismo encontrava-se enfraquecido no estado do Rio de Janeiro, era maior o apoio à Light, por meio da influencia do prefeito da cidade do Rio de Janeiro, Distrito Federal, o engenheiro Souza Aguiar, permitindo à The Rio de Janeiro Trammway Light and Power Co. Ltd a consolidação dos seus negócios ancorada nas concessões que havia comprado. Por outro lado, no período subsequente (1909 - 1910) em que há o fortalecimento do nilismo no Estado do Rio de Janeiro, no momento em que Nilo Peçanha assume a presidência do país, a Guinle \& Cia/CBEE conseguiu criar as possibilidades reais de alavancar seus horizontes econômicos.

Diante deste panorama de disputas políticas o campo jurídico se faz presente, Hansen (2012) aponta que a Guinle \& Cia/CBEE foi progressivamente perdendo todos os seus recursos judiciais possíveis à medida que o conflito ia se aprofundando. De acordo com Hansen:

Em 1909, a justiça local impediu que Guinle\&Cia/CBEE realizasse obras para atender aos contratos firmados com repartições federais, pois tanto no Juízo dos Feitos da Fazenda Municipal, através do juiz Joaquim Saraiva Júnior, quanto na primeira vara cível, através do juiz Pedro Francellino, despacharam sempre favoravelmente à "The Rio Light/SAG", inclusive esse último teve sua decisão confirmada pela Suprema Corte de Apelação. Apenas na justiça federal, através do juiz Godofredo 
Cunha, o pedido Interdito Proibitório da "The Rio Light" foi negado, alegando o juiz que não poderia interferir na questão. Em 1910, o juiz federal Raul de Souza Martins concedeu Mandado de Manutenção de Posse para proteger obras, áreas e outros da SAG, em 23/03/1910, mas a CBEE/Guinle\&Cia agravou dessa decisão no Supremo Tribunal Federal, tendo sido o agravo negado, em 20/04/1910, numa votação de 9 contra 1. Além desses, cabe mencionar dois dos processos movidos pela "The Rio Light" contra a Guinle\&Cia/CBEE: o de Manutenção de Posse contra a Guinle\&Cia, CBEE e Municipalidade, que tramitou de 1910 a 1915 no Juízo dos Feitos da Fazenda Municipal e foi julgado procedente, e o de Interdito Proibitório contra a Guinle\&Cia e CBEE, para que não fossem assentadas linhas de transmissão para cumprir o contrato com o Ministério da Marinha, que tramitou de 1910 a 1912 no Juízo Federal, julgada também procedente. (HANSEN, 2012, p.230-231)

Hansen é enfática ao tratar do enfraquecimento dos Guinle e aponta para seu desfecho conclusivo,

Portanto, de 1907 a 1915, no Judiciário, a Guinle\&Cia/CBEE não teve sucesso. Na justiça do Distrito Federal, em nenhum momento a empresa ganhou qualquer espaço. E na federal, também não. Godofredo Cunha, por exemplo, como juiz da primeira vara federal, negou um Interdito à "The Rio Light", em 1909, mas logo depois, como membro do Supremo Tribunal Federal, em 1910, quando da votação do agravo da CBEE contra a decisão de Raul de Souza Martins que concedeu Interdito Proibitório contra a Guinle\&Cia/CBEE, votou contra o agravo. Caso idêntico se verificou com Pedro Lessa e Amaro Cavalcanti. O primeiro votou, em 1908, pela existência do conflito de jurisdição entre a justiça federal e do Distrito Federal, o que era de interesse dos Guinle, enquanto o segundo votou pela não existência do dito conflito; em 1910, enquanto Pedro Lessa votou contra o agravo da CBEE, Amaro Cavalcanti foi favorável. (HANSEN, 2012, p.231)

70 Após o enfraquecimento político e jurídico, os Guinle, não por escolha, deram espaço à concorrente canadense no que diz respeito ao setor elétrico brasileiro, e com isso, em 1927 a Companhia Brasileira de Energia Elétrica é comprada pela empresa American and Foreign Power Company Inc. (AMFORP) de capital estadunidense.

71 A partir destes fatos, a AMFORP traça um planejamento após a adquirir a CBEE - assim como outras várias concessionárias de energia que foram adquiridas no Rio e em São Paulo - ou seja, como estratégia adotada pela AMFORP, a CBEE se interliga com a The Rio de Janeiro Trammway Light and Power Co. Ltd, utilizando desta interligação para ampliar sua rede de negócios e com isso minimizar, enfim, os desgastes advindos da concorrência.

72 No entanto, o comando da AMFORP não foi tão duradouro, pois em 1964 os militares intervêm no governo, dando o golpe que depôs João Goulart. $O$ golpe militar trouxe reflexos para a AMFORP, justamente porque os militares estatizaram a empresa que controlava a CBEE, tornando-a pública, passando a sua administração para o governo estadual. Já em 1979, quando o Presidente Geisel passou o governo para as mãos do Presidente Figueiredo, os militares firmavam outra mudança neste setor: a CBEE passou a assumir os serviços de eletrificação rural do estado, antes prestados pelas Centrais Elétricas Fluminenses SA, produzindo assim a fusão das empresas, que deu origem à Companhia de Eletricidade do Rio de Janeiro, a CERJ.

Após o período da ditadura militar, no governo Collor (década de 90), foi aprovada a Lei nº 8.031/1990, que promoveu o Programa Nacional de Desestatização, com o objetivo de reduzir o aparato administrativo do governo. Foi o início de um período em que predominou a ótica do neoliberalismo, de reduzir a presença do Estado, de deixar o "Estado menor" utilizando-se do discurso entreguista de que empresas privadas 
cumprem suas funções com maior velocidade e com isso seriam capazes de aprimorar e expandir seus serviços. Assim, em 1996, o Rio de Janeiro teve a sua primeira empresa eletrica privatizada: a CERJ. O governo Marcello Alencar (1995-1998) foi o responsável pelo leilão da estatal que, mais uma vez, mudou de mãos, indo novamente para o controle privado.

A Companhia de Eletricidade do Estado do Rio de Janeiro (CERJ) fora privatizada em leilão no dia 20 de novembro de 1996, e a partir do leilão mudou sua denominação, inicialmente para Ampla, uma empresa de capital aberto, com sua sede em Niterói-RJ, que atualmente é chamada de Enel Distribuição Rio, que é a sua principal acionista. A Enel Distribuição Rio faz parte da Enel Brasil, fundada em 2005, tratando-se de uma empresa brasileira do ramo de energia elétrica controlada pelo grupo italiano Enel, com sede em Roma, fundada em 1962. A Enel Brasil S.A centraliza as participações societárias do grupo Enel no território brasileiro.

Atualmente, no ano de 2020, a Enel Distribuição Rio é a empresa responsável pelo abastecimento energético em grande parte do estado do Rio de Janeiro onde concorre com outras empresas, são elas: a Light e a ENERGISA, sendo está última uma holding, empresa de capital aberto, do gênero - Sociedade Anônima - com atuação no setor elétrico no município de Nova Friburgo - RJ desde 2008. Como pode ser visto na figura 7.

Figura 7 - Cartograma sobre a distribuição por empresa do fornecimento de energia elétrica nos municííos do estado do Rio de Janeiro

\section{Empresas distribuidoras de energia elétrica no Estado do Rio de Janeiro}

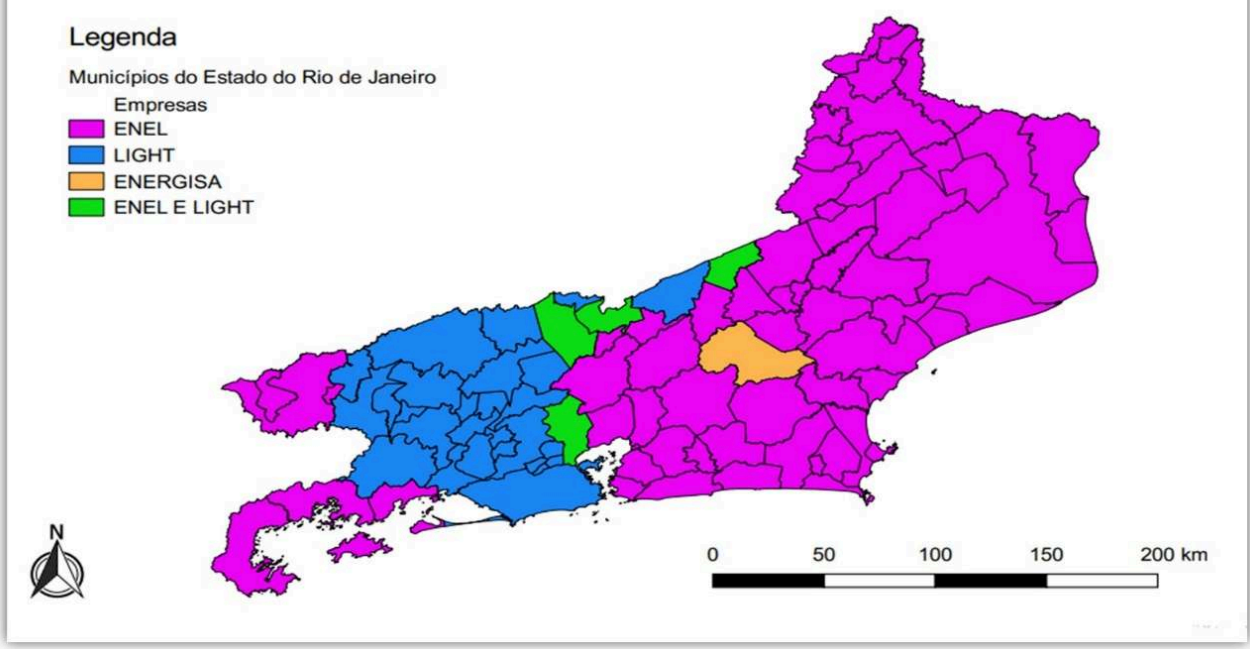

FONTE: Site oficial das empresas de energia. ELABORAção: CANDIDO, D'jeanine, 2020

\section{Considerações finais}

Com efeito, cabe reafirmar a importância de se compreender a relevância da rede técnica proveniente da eletrificação enquanto setor produtivo, no momento em que se desenvolvia a chamada revolução técnico-cientifica, o que trouxe melhorias e modernizações em grande escala, principalmente em países periféricos como o Brasil. Oliveira (2019) aponta para tais fatos, destacando, 
A importância da eletricidade como rede técnica essencial em países periféricos também. A chamada revolução técnico-científica, mencionada no corpo do texto, representou uma importante alteração dos padrões produtivos e uma significativa mudança na composição orgânica das forças produtivas, que modificaram as matrizes energéticas até então dominantes. Em países periféricos, no entanto, o petróleo e seus derivados em termos combustíveis e petroquímicos, bem como a incorporação imediata de motores à combustão e outros segmentos industriais que começam a despontar no início do século, não produzem efeitos diretos em nossa economia. Mas a incorporação da energia elétrica, uma das manifestações mais avançadas em todos os países em termos de inovações científicas, chega ao Brasil no mesmo período. A modernização dos sistemas de transportes urbanos, a eletrificação de indústrias, prédios e residências, e a incorporação de grandes obras de engenharia começam a criar elementos capazes de produzir certo dinamismo na estrutura urbana e estimular usos dessa "nova" matriz em estruturas produtivas (SAES, 2015). Evidentemente, outros fatores foram determinantes, mas, para nós, é inegável que a revolução técnico-científica no Brasil teve início com a produção em larga escala da energia elétrica. (OLIVEIRA, F.G. 2019, p. 190)

Ao investigar a eletrificação do leste metropolitano foi possível compreender, a partir dos aspectos históricos, como se iniciou o processo de eletrificação (destacado a trajetória histórica até a consolidação da energia elétrica), por onde começou este processo, evidenciando quais os motivos e interesses que permeavam a eletrificação e, concomitantemente, os reflexos da eletrificação para a sociedade e para a indústria brasileira. $\mathrm{O}$ objetivo foi identificar quem foram os agentes responsáveis pelo processo que envolve uma ampla cadeia produtiva, que é a rede técnica do setor da eletrificação, bem como analisar a concorrência e as associações empresariais, levando em conta as estratégias que utilizaram, a especificidade que envolve o leste metropolitano devido às ações da família Guinle/Gafreé e o papel do Estado para com as empresas, elaborando desta forma uma trajetória histórica que delimita-se do ano de 1879 até 2020.

\section{BIBLIOGRAFIA}

BERENGUER Gangolells Alseda. Els territoris del negoci elèctric: el model de Pearson i la seva aplicació a Sao paulo, México D.F., Rio de janeiro i Barcelona. Barcelona, Tesis, Universitat Politècina de Cataluña. Departamento d'Infraestructura del transporti del territotori. 2008. <http://hdl.handle.net/2099.1/5773>

CASTILHO, Denis. Redes e processos espoliativos no Centro-Norte do Brasil. In: OLIVEIRA, F G. et al (Orgs). Espaço e Economia: Geografia econômica e política / organizado.Rio de Janeiro: Consequência, 2019, p.295-320.

CATAIA, Márcio. Macrossistema elétrico brasileiro: integração nacional e centralização do poder. In: CAPEL, Horacio; ZAAR, Miriam (Coords. y Eds.) La electricidad y la transformación de la vida urbana y social. Portugal, Évora : Geocrítica, 2019, p. 581-602.

CURRIEN, N. \& GENSOLLEN, M. Redes de telecomunicações e planejamento espacial. Revista Geográfica do Oriente, 1985. № 1, p. 47-56. 
DIAS, Leila C. Redes: emergência e organização. In,: CASTRO, Iná E. et al (Orgs). Geografia: conceitos e temas. Rio de Janeiro: Bertrand Brasil, 2000.

HANSEN, Cláudia Regina Salgado de Oliveira. Eletricidade no Brasil da Primeira República: a Companhia Brasileira de Energia Elétrica e os Guinle no Distrito Federal (1904-1923) / Tese. Universidade Federal Fluminense. Rio de Janeiro - 2012. $284 \mathrm{f}$.

HARNECKER, Marta. O capital: conceitos fundamentais. Global, 1978, 296 p.

LAMARÃO, Sérgio Tadeu de Niemeyer. A energia elétrica e o parque industrial carioca (1880-1920). Niterói: Tese de Doutorado - UFF, 1997.

MANSUR, Andre Luis. E fez-se a luz nas ruas do Rio. In: newsletter \#Colabora. 21 de março de 2017. Disponível em: https://projetocolabora.com.br/ods7/a-luz-eletrica-e-a-vida-no-rio/. Acesso em: 14 jul. 2020.

MELLO, João M. C. O Capitalismo tardio. São Paulo: Brasiliense, 1998.

OLIVEIRA, F.G. A geração de energia elétrica - Represas e usinas - E redes técnicas de energia e abastecimento de água dela decorrentes no Rio de Janeiro - 1940 a 1960. In: In: CAPEL, Horacio; ZAAR, Miriam (Coords. y Eds.) La electricidad y la transformación de la vida urbana y social. Portugal, Évora : Geocrítica, 2019, p. 175-192.

RAFFESTIN, Claude. Por uma geografia do poder. Tradução de Maria Cecília França. São Paulo: Ática, 1993.

ROCHA, Amara Silva de Souza. A chegada da energia elétrica no Rio de Janeiro. In: História viva: Revista de História da Biblioteca Nacional. Rio de Janeiro, 19 jun. 2009. Disponível em: http:// historianovest.blogspot.com/2009/06/chegada-da-energia-eletrica-no-rio-de.html. Acesso em: 14 jul. 2020.

RUFINO, Marcio. Redes técnicas, territórios e escalas: leituras sobre modernização e crítica da economia política do espaço. In: Espaço e Economia: Geografia econômica e política / organizado por: Floriano José Godinho de Oliveira ... [ et al ]. - Rio de Janeiro: Consequência, 2019, p. 271-294.

SANTOS, M. A natureza do espaço - Técnica e tempo, razão e emoção. São Paulo: Ed. Hucitec, SP. 1996

SILVEIRA, Rogério Leandro Lima da. Redes e território: uma breve contribuição geográfica ao debate sobre a relação sociedade e tecnologia. Revista bibliográfica de geografía y ciencias sociales, Universidad de Barcelona, Vol. VIII, nº 451, 15 de junho de 2003.

WEID, Elisabeth Von der. A interferência da eletrificação sobre a cidade: Rio de Janeiro (1857-1914). Fundação Casa de Rui Barbosa. Rio de Janeiro, 2003. Disponível em: http:// www.abphe.org.br/arquivos/2003_elisabeth_von_der_weid_a-interferencia-da-eletrificacaosobre-a-cidade-rio-de-janeiro-1857_1914.pdf . Acesso em: 14 jul 2020.

\section{NOTAS}

1. Referência aos passeios na avenida central, Largo do Paço Imperial e ruas no centro após a Reforma Pereira Passos no centro da cidade do Rio de Janeiro. 


\section{RESUMOS}

O processo de eletrificação do Rio de Janeiro envolveu diversos agentes sociais, em especial no leste metropolitano. Este artigo investiga e identifica os agentes, as redes técnicas e usinas geradoras de energia que propiciaram a produção e distribuição de energia elétrica no estado. Identifica também a disputa pelo domínio deste fornecimento e o estabelecimento de uma complexa cadeia produtiva na região estudada, desvelando as extensas relações de poder que envolveram as administrações públicas do estado e do Distrito Federal. Por fim, buscou-se traçar um panorama histórico sobre como se deu o processo de eletrificação e modernização do território do Rio de Janeiro.

El proceso de electrificación en Río de Janeiro involucró a varios agentes sociales, especialmente en el oriente metropolitano. Este artículo investiga e identifica los agentes, redes técnicas y plantas generadoras de energía que proporcionaban la producción y distribución de energía eléctrica en el estado. También identifica la disputa por el dominio de esta oferta y el establecimiento de una compleja cadena productiva en la región estudiada, desvelando las extensas relaciones de poder que involucraron a las administraciones públicas del estado y del Distrito Federal. Finalmente, se intentó trazar un panorama histórico de cómo se desarrolló el proceso de electrificación y modernización del territorio de Río de Janeiro.

Cet article vise à identifier les agents, les réseaux techniques et les usines d'électricité dans le territoire de Rio de Janeiro, ainsi que les disputes par le domaine de la chaîne productive et territoriale. Sous le point du vue historique, on peut conclure que l'électrification a été cruciale pour le processus de modernisation subie par le Rio de Janeiro.

The electrification process in Rio de Janeiro involved divers social agents, especially in the metropolitan east. This article investigates and identifies the agents, technical networks and power generating plants that provided the production and distribution of electricity in the state. It also identifies the dispute for the domain of this supply and the establishment of a complex productive chain in the studied region, unveiling the extensive power relations that involved the public administrations of the state and of the Federal District. Finally, an attempt was made to draw a historical overview of how the process of electrification and modernization of the territory of Rio de Janeiro.

\section{ÍNDICE}

Palavras-chave: eletrificação, redes técnicas, leste metropolitano, Light, Enel Mots-clés: L'électrification, réseaux techniques, l'Est métropolitain, Light, Enel

Palabras claves: electrificación, redes técnicas, este metropolitano, Light, Enel

Keywords: electrification, technical networks, metropolitan east, Light, Enel

\section{AUTOR}

\section{MATHEUS AREIAS DA SILVA}

Bolsista de Iniciação Científica do CNPq. Faculdade de Formação de Professores - UERJ. Email:mat.areias@gmail.com 